Check for updates

London

Cite this as: $B M J 2021 ; 372: n 15$ http://dx.doi.org/10.1136/bmj.n15 Published: 05 January 2021

\section{Covid-19: London's Nightingale Hospital will reopen for non-covid cases}

Jacqui Wise

London's NHS Nightingale Hospital is currently being repurposed to take patients without covid-19 who are recovering from operations and procedures, to help relieve the unprecedented demand for beds in the capital.

Since Christmas, hospitals in London and the south east have come under significant pressure from high covid-19 infection rates, with one hospital trust forced to cancel some cancer operations and another now operating in "disaster medicine mode."

During the first wave of the pandemic the Nightingale Hospital London, based at the ExCeL centre, was set up to take patients with covid-19 requiring critical care. However, only 51 patients were treated at the facility before it was closed in May. ${ }^{1}$

A spokesperson for the NHS in London told The BMJ, "We are working hard to prepare NHS Nightingale Hospital London to take patients if necessary. It will provide rehabilitation for people who are recovering after an emergency hospital stay and who are not covid positive, freeing up other beds in hospital for covid patients."

Newspapers have reported that only 300 beds will be available at the hospital, and questions have been raised about where the staff will come from. The NHS spokesperson said that the reopening date was under daily review, as the numbers of beds will be determined by demand and the availability of staff. As the hospital will provide a different type of care from that provided in the first wave, its facilities and layout will need to be different.

King's College Hospital NHS Foundation Trust is believed to be the first to cancel some cancer operations as well as all elective procedures. A spokesperson said, “A small number of cancer patients due to be operated on this week have had their surgery postponed, with patients being kept under close review by senior doctors."

\section{Envisaged purpose}

In October 2020 the Nightingale hospital in Manchester also reopened for non-covid-19 patients, acting as a step-down facility for patients discharged from general and surgical wards. ${ }^{2}$ Patients are also currently being treated in Nightingale hospitals in Exeter, Bristol, and Harrogate, said the NHS spokesperson, who declined to give details about how many people were currently being treated.

Nick Scriven, president of the Society for Acute Medicine, told The BMJ, "It is positive to see the NHS now finally make a decision on the purpose of Nightingale hospitals, but the suggestion that they may now be used as rehabilitation centres for non-covid patients, as is apparently the case in London, is far from their envisaged purpose.”

The hospitals were originally intended for use as mini intensive care units, he said, "but everyone was aware there were not enough highly skilled critical care staff to be moved out of hard pressed hospitals and maintain safe staffing ratios.”

Hospitals in London and the south east are facing high demand for beds because of high covid-19 infection rates arising from the spread of the new variant. An email leaked to Sky News said that intensive care units at three hospitals-North Middlesex University Hospital, Barnet Hospital, and Whittington Hospital-were "full” on New Year's Eve and that patients had to wait to be transferred to other hospitals for critical care. ${ }^{3}$ Another leaked internal email from the Royal London Hospital said that it was in "disaster medicine mode" and no longer able to provide a high standard of critical care. ${ }^{4}$

On 29 December Bart's Health NHS Trust said that it had moved into a "very high pressure phase." The trust opened a further ward at the Royal London Hospital specifically to care for patients with covid-19, and it has stood down all routine planned care and redeployed staff to critical care and covid wards. On 21 December the Royal Free London NHS Trust paused all non-urgent planned procedures and operations.

\section{Reduced flexibility}

The former health secretary Jeremy Hunt said that a third more hospital beds nationwide were now being taken up by covid patients than in the first wave-and this figure was $50 \%$ higher in the greater south east of England. He wrote on Twitter: "To those arguing winter is always like this in the NHS: you are wrong. I faced four serious winter crises as Health Sec and the situation now is off-the-scale worse than any of those."

Daniele Bryden, vice dean of the Faculty of Intensive Care Medicine, told The BMJ that using the Nightingale hospitals for non-covid elective pathways "makes sense." She said that this was a logical approach given the importance of keeping covid and non-covid patients separate, which has reduced the flexibility of hospitals and the number of available beds.

"We have been saying right from the beginning of the pandemic that there are a finite number of intensive care beds," she said. "Even though on paper the beds have been expanded and surge capacity identified, there are no more staff in terms of nurses and doctors. 
"Staff resilience is a concern, in terms of physical and mental health. Critical care staff have been under sustained pressure since last March.”

1 Day M. Covid-19: Nightingale hospitals set to shut down after seeing few patients. BMJ 2020;369:m1860. doi: 10.1136/bmj.m1860 pmid: 32381503

2 Torjesen I. Manchester's Nightingale hospital reopens to non-covid patients. BMJ2020;371:m4224 doi: 10.1136/bmj.m4224 pmid: 33122167

3 Manthorpe R. Covid-19: Three intensive care units in London "full" on New Year's Eve, leaked email shows. Sky News 2021 Jan 2. https://news.sky.com/story/covid-19-three-intensive-careunits-in-london-full-on-new-years-eve-leaked-email-shows-12177002.

4 Gibbons K. Covid-19 rulebreakers told they have blood on hands. Times 2021 Jan 1.

https://www.thetimes.co.uk/article/hospitals-move-to-covid-19-disaster-mode-amid-staffshortages-k6xl830bm.

This article is made freely available for use in accordance with BMJ's website terms and conditions for the duration of the covid-19 pandemic or until otherwise determined by BMJ. You may use, download and print the article for any lawful, non-commercial purpose (including text and data mining) provided that all copyright notices and trade marks are retained. 